\title{
Age-Related Effects of Scopolamine on REM Sleep Regulation in Normal Control Subjects: Relationship to Sleep Abnormalities in Depression
}

\author{
Uma Rao, M.D., Preetam Lutchmansingh, Ph.D., and Russell E. Poland, Ph.D.
}

In order to assess the influence of development on the regulation of rapid eye movement (REM) sleep by cholinergic systems, the REM sleep responses to scopolamine were assessed in five normal adolescent and seven adult control subjects in this preliminary investigation. Subjects were studied on two separate occasions for three consecutive nights. Subjects received placebo or scopolamine (1.5 ug/kg, i.m.) on night 2 ; night 3 was considered the "recovery" night. As expected, scopolamine delayed REM latency and suppressed REM sleep on night 2 in both the adolescents and adults. Subtle developmental differences occurred, with scopolamine having a tendency to suppress REM sleep less effectively in younger subjects. On night 3, REM latency was shortened and REM sleep was increased to comparable extent in both the adolescents and adults. The comparable REM sleep responses to scopolamine between normal adolescents and adults, particularly on night 3 , are discussed in relation to the age-related expression of REM sleep abnormalities in depression. [Neuropsychopharmacology 21:723-730, 1999] (C) 1999 American College of Neuropsychopharmacology. Published by Elsevier Science Inc.
KEY WORDS: Adolescents; Adults; Cholinergic; Development; REM sleep; Scopolamine

Electroencephalographic (EEG) sleep changes associated with major depressive disorder are among the most well replicated findings in adult patients (for a review, see Benca et al. 1992). Perhaps the most dramatic changes occur with respect to rapid eye movement (REM) sleep measures.

From the Department of Psychiatry (UR, PL, REP), Harbor-UCLA Medical Center, Torrance, CA; and Department of Psychiatry (UR, REP) and Brain Research Institute (UR, REP), UCLA School of Medicine, Los Angeles, CA.

Address correspondence to: Uma Rao, M.D., UCLA Neuropsychiatric Institute, 760 Westwood Plaza, Room 68-237, Los Angeles, CA 90024-1759.

Received December 1, 1998; revised April 9, 1999; accepted June 7, 1999 .
Despite the evidence for continuities in mood disorders across the life span (Kovacs 1996), the manifestation of comparable REM sleep abnormalities appears to occur less frequently in early onset depression (reviewed in Rao et al. 1996). The mechanisms for this disparity are unclear. One possibility is that circadian and ultradian rhythms are more desynchronized in youngsters with depression, thus not allowing the REM sleep abnormalities, particularly the shortening of REM latency, to be easily detected (Teicher et al. 1993). Another possibility is that slow-wave sleep pressure is greater than REM sleep pressure in youngsters so that the shortening of REM sleep latency is constrained (Borbely 1982).

Furthermore, it is possible that the neurotransmitter circuitry involved in REM sleep regulation is not fully mature in youngsters. Thus, shortened REM latency or increased REM activity and density in depression 
might not be able to occur. Animal studies suggest that the cortical cholinergic projections may be the last developing components of the reticular core (Coyle and Yamamura 1976). We previously found that the delay in REM latency in response to scopolamine, a non-specific muscarinic cholinergic antagonist, occurs to comparable degrees in both normal adolescents and adults suggesting that muscarinic cholinergic tone is working in both age groups (McCracken et al. 1997; Poland et al. 1997). Similarly, the REM sleep response to scopolamine, particularly REM latency, also is relatively intact in adult and adolescent patients with depression (McCracken et al. 1997; Poland et al. 1997).

In contrast to scopolamine, adults with major depression show an enhanced shortening of REM latency in response to cholinergic agonists, and one study indicates that this abnormal response also is observed in prepubertal children (Dahl et al. 1994). However, it still remains unclear as to why the majority of studies in depressed youngsters have not shown the typical REM sleep abnormalities, particularly shortened REM latency, which are observed in adult depressed patients.

Developmental differences in REM sleep manifestations associated with depression may have implications for the treatment of depression in youngsters. Compared to adults, children and adolescents suffering from depression appear to respond less robustly to traditional antidepressant treatments (for a review, see Birmaher et al. 1996). At least in adults, one feature common to many antidepressants is the ability to suppress REM sleep and prolong REM latency (Sharpley and Cowen 1995; Staner et al. 1995; Vogel et al. 1990). Some investigators have suggested that baseline REM sleep characteristics, as well as the extent of REM sleep suppression on acute antidepressant treatment are predictive of subsequent antidepressant efficacy (Gillin et al. 1978; Höchli et al. 1986; Kupfer et al. 1994; Rush et al. 1989; Sharpley and Cowen 1995; Thase et al. 1997; Vogel et al. 1990). Even in children and adolescents, there is preliminary evidence that baseline reduced REM latency and REM sleep suppression on administration of antidepressants may be predictive of antidepressant treatment response (Emslie and Kowatch 1996; Kupfer et al. 1979). However, baseline reduced REM latency and REM sleep suppression with antidepressant treatment may be less prevalent in juvenile populations (Armitage et al. 1997; Benca et al. 1992; Knowles and MacLean 1990; Rao et al. 1996).

In addition to REM sleep suppression on acute antidepressant administration, other adaptive changes occur in adults. For example, withdrawal from antidepressants and cholinergic antagonists results in temporary increase in REM sleep (Gillin et al. 1991a; Sagalés et al. 1975; Salin-Pascual et al. 1993; Sharpley and Cowen 1995; Staner et al. 1995; Vogel et al. 1990). To our knowledge, there are no studies on the withdrawal effects of antidepressants or anticholinergics on REM sleep in children or adolescents. One study noted that discontinuation of clomipramine in young rats after a twoweek treatment during the neonatal period was not accompanied by "rebound" increase in REM sleep (Mirmiran et al. 1981). Although data from animals may not be applicable to humans, this observation, together with other EEG sleep findings in children and teenagers, suggests that there may be developmental differences in REM sleep regulation.

In order to study this issue further, in this pilot study, sleep patterns in normal adolescents and adults were studied following the administration of scopolamine and on the recovery night. Of particular interest was whether adolescents demonstrate acute shortening of the REM latency and other REM rebound effects on the recovery night to the same degree as adults.

\section{MATERIALS AND METHOD}

\section{Participants}

A total of 12 subjects between the ages of 14 and 42, five adolescents (ages: 14-18) and seven adults were studied. All participants were evaluated for psychopathology with the Structured Clinical Interview for DSM-III-R (SCID) (Spitzer et al. 1986). Also, psychopathology in the first-degree relatives was assessed, using the subject or parent (in the case of adolescents) as an informant. In addition to the SCID interview, the clinician rated the severity of depressive symptoms using the Hamilton Depression Rating Scale (HDRS) (Hamilton 1960).

The subjects had no personal history of a major psychiatric disorder or history of a major psychiatric disorder in any known first-degree relative. All participants had HAM-D scores $<2$. Subjects were medically healthy, as determined by physical examination, electrocardiogram, full chemistry panel, thyroid function tests, and urine drug screens. All participants were free from medication use for at least two weeks. In order to rule out known sleep disorders, a sleep questionnaire was filled-out and a sleep log was maintained for at least one week prior to the study. Subjects with a personal history of a major sleep disorder or a family history of narcolepsy were excluded from the study. Participants were screened also for the presence of sleep disorder(s) on the first night of the sleep protocol.

\section{Sleep Protocol and Scoring of Sleep Records}

Subjects were studied twice for three consecutive nights, approximately one week apart. On all nights, conventional EEG electrodes were attached by 8:00 PM, and sleep recordings were made from 11:00 PM (lights out) to 7:00 AM. On night 2 of each three-night session, subjects were administered either saline or scopolamine 
$(1.5 \mu \mathrm{g} / \mathrm{kg}, \mathrm{i} . \mathrm{m}$.$) at 11:00 PM in a double-blind, random-$ ized fashion. Night 3 was considered the recovery night.

Sleep records were coded and scored blindly according to standard criteria (Rechtschaffen and Kales 1968). REM latency was calculated using lenient and strict definitions. For the lenient definition, REM latency was defined as the time between sleep onset (the first minute of any stage of sleep) and the first 30 seconds of REM sleep. The strict definition was defined as the time between sleep onset (first minute of stage 2 or deeper sleep, followed by at least 9 minutes of stage 2 or deeper sleep, interrupted by no more than 1 minute of waking or stage 1) and the first REM period 3 minutes in length. Other REM measures, including REM activity and REM density, and additional sleep variables were scored according to the criteria of Kupfer (1976), as was done previously (Poland et al. 1989, 1997).

\section{Statistical Analysis}

Statistical analyses were performed utilizing two-way analysis of variance (ANOVA) with repeated measures, with adolescent versus adult as the between-subjects factor, whereas drug (placebo versus scopolamine) and night (treatment versus recovery) were the within-subject factors.

Due to modest sample sizes, analyses were restricted to the REM sleep measures based on a priori hypotheses. Where significant main and/or interaction effects for group, drug or night were observed, separate analy- ses were performed, using unpaired and paired $t$-tests, to locate significant differences. Alpha was set at 0.05 . Pearson product-moment correlation coefficients were calculated to examine the relationship between age and change in REM sleep measures on treatment and recovery nights (delta REM sleep measures). Transformations were performed when data were not normally distributed. Only EEG data from the second and third nights of each three-night session were used in the statistical analyses, the first night being considered as an adaptation night.

\section{RESULTS}

\section{REM Sleep Responses to Scopolamine in Adolescents versus Adults}

Variables for the first REM episode on placebo and scopolamine nights as well as the recovery nights, in both adolescents and adults, are presented in Table 1. Baseline REM sleep measures were comparable between adolescents and adults. REM latency was effected by scopolamine. With the exception of REM duration, there was a main effect of the night on REM sleep measures. Furthermore, there was a significant drug $\times$ night interaction for REM latency and REM density. Compared to the placebo night, scopolamine prolonged REM latency, whereas it diminished REM activity and REM density in the adults. A similar trend was noted for all three measures in the adolescents, but they did not approach significance level. There was a significant re-

Table 1. REM Sleep Variables for First REM Episode (Mean \pm SD) Following Placebo and Scopolamine (1.5 $\mu \mathrm{g} / \mathrm{kg}, \mathrm{i} . \mathrm{m}$.

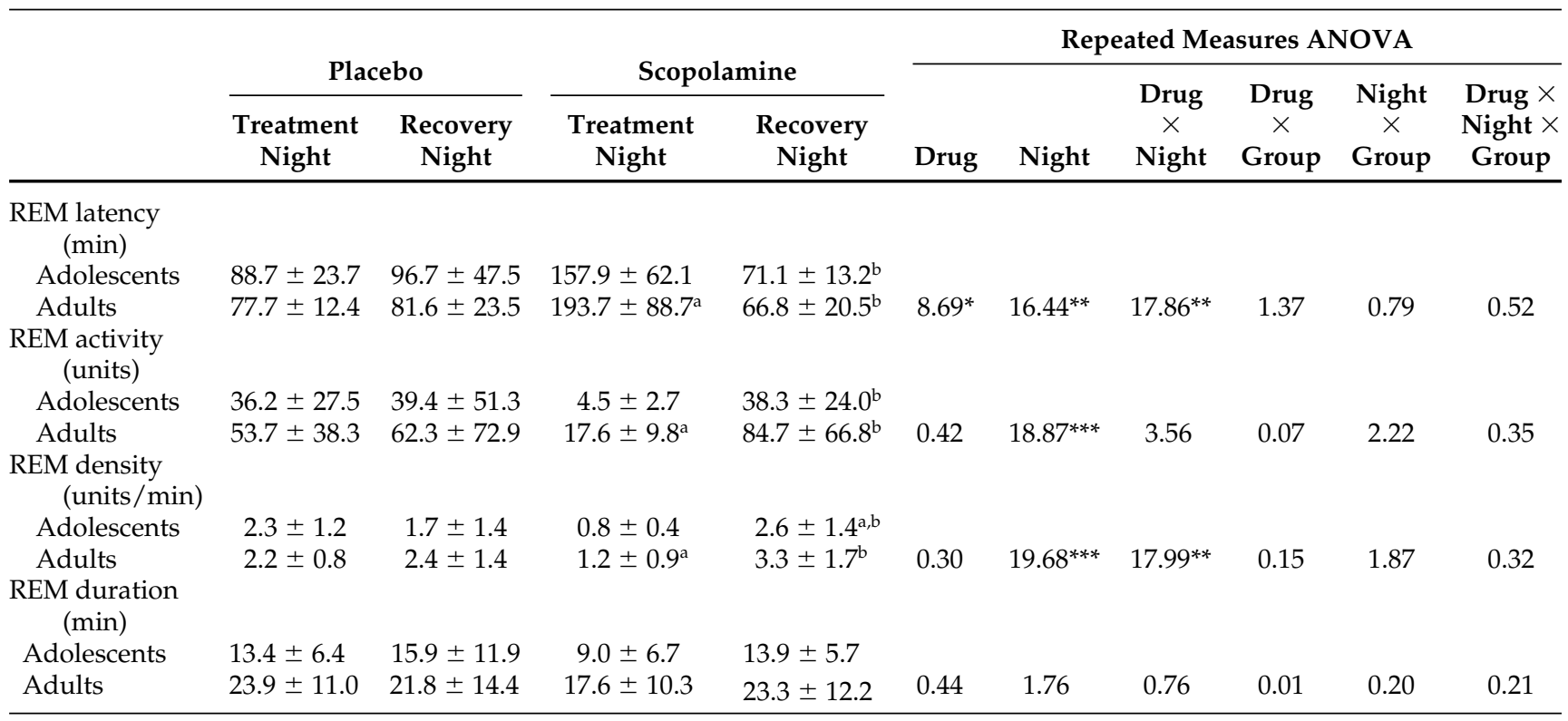

$*=p \leqslant .05 ;{ }^{* *}=p \leqslant .005 ;{ }^{* * *}=p \leqslant .001$.

${ }^{\mathrm{a}} p \leqslant .05$, placebo versus scopolamine, same night; ${ }^{\mathrm{b}} p \leqslant .05$, treatment versus recovery night, scopolamine. 


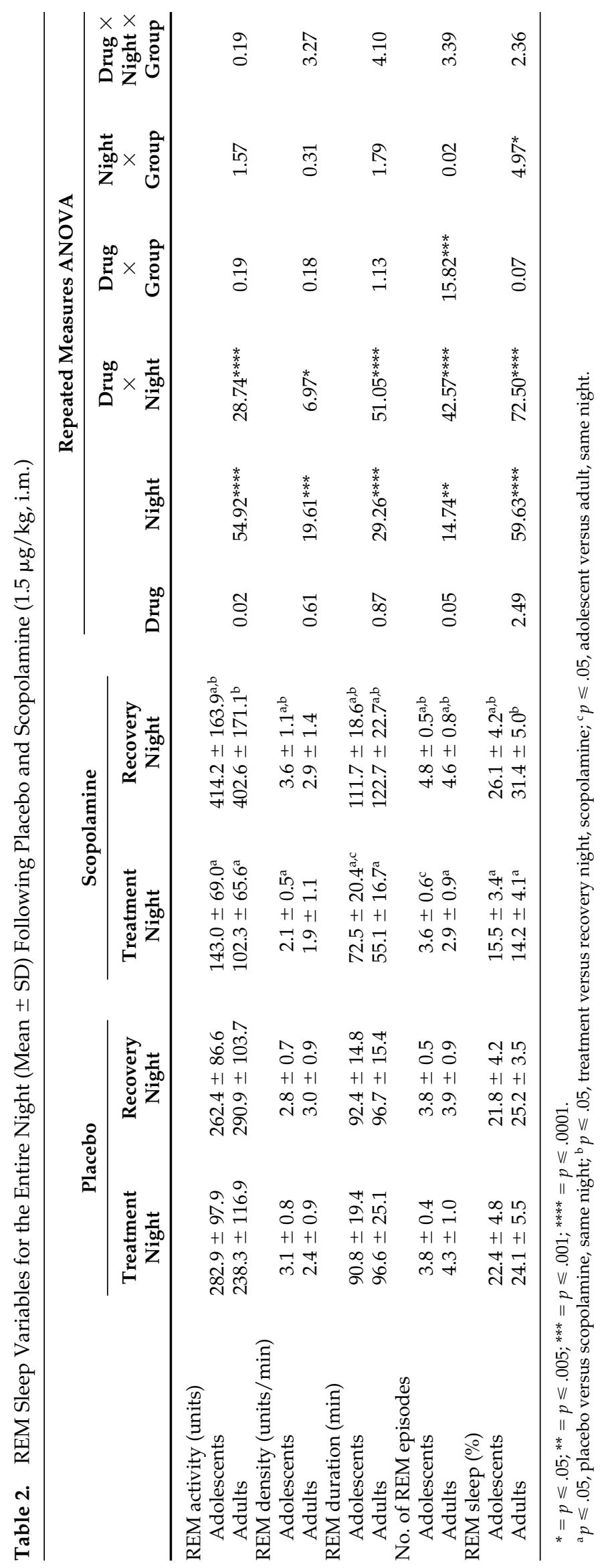


bound effect for all three measures on the recovery night following scopolamine treatment. The rebound effect was comparable between adolescents and adults. Among adolescents, the rebound effect in REM density was significantly greater than the placebo recovery night.

Table 2 shows REM sleep measures for the entire night during placebo and scopolamine treatments, as well as recovery nights, in both adolescents and adults. Baseline REM sleep measures were comparable between the two groups. There was a main effect of the night and drug $\times$ night interaction for each of the REM sleep measures. Again, scopolamine suppressed all aspects of REM sleep over the course of the night. Although no significant drug $\times$ night $\times$ group interactions occurred, some trends were present. With the exception of REM density and REM episode variables, the extent of REM sleep suppression was comparable between adolescents and adults. Reduction in REM density in the adults did not reach significance. Adolescents did not demonstrate reduction in REM episodes. On the scopolamine night, adolescents showed longer REM duration and more REM episodes compared to the adults. There was a significant rebound effect for all REM sleep measures on the recovery night following scopolamine treatment. Overall, the two groups did not differ significantly on the degree of rebound effect. In comparison with the placebo rebound effects, adolescents showed a trend for an even greater increase in all the REM sleep variables. In the adults, only REM duration and REM episodes were greater than the effects observed on the placebo rebound night.

\section{Relationship between Age and REM Sleep Responses to Scopolamine}

Pearson correlation coefficients between age and delta REM sleep variables on the treatment night revealed marked variability (see Table 3 ). Only total REM duration showed a significant correlation with age. In summary, younger subjects showed less REM sleep suppression with scopolamine treatment, specifically in the tonic REM sleep measures. Phasic REM sleep measures (namely, delta REM activity and delta REM density) showed weak relationships with age. In examining the association between age and delta REM sleep measures on the recovery night, none of the variables were significantly influenced by age. The correlation coefficients were of small magnitude (range -0.22 to +0.18 ). Delta REM latency on the recovery night plotted against age is depicted in Figure $1(r=0.18, d f=11, \mathrm{NS})$.

\section{DISCUSSION}

To our knowledge, this is the first study to directly compare and contrast REM sleep responses to a phar-
Table 3. Relationship between Age and Delta REM Sleep Measures with Scopolamine Treatment

Correlation Coefficient

\begin{tabular}{lr}
\hline FIRST REM EPISODE & \\
REM latency & 0.46 \\
REM activity & -0.28 \\
REM density & 0.30 \\
REM duration & -0.30 \\
ALL REM EPISODES & \\
REM activity & -0.14 \\
REM density & 0.20 \\
REM duration & $-0.60^{*}$ \\
Number of REM episodes & -0.54 \\
REM sleep (\%) & -0.56
\end{tabular}

${ }^{*} p \leqslant .05$.

macologic challenge simultaneously in adolescents and adults. Moreover, we are not aware of any studies exploring the effects on the recovery night following a single dose of scopolamine administration. For the most part, scopolamine delayed the onset of REM sleep, as well as suppressed REM sleep and phasic REM activity to comparable extent in both adolescents and adults. Furthermore, rebound effects were comparable in the two groups. There were, however, subtle developmental differences. Younger subjects tended to show less REM sleep suppression with scopolamine administration, specifically with respect to tonic REM sleep measures. There was also a tendency for the adolescents to demonstrate greater degree of rebound effects on the recovery night, particularly on phasic REM sleep measures. These results suggest that the muscarinic cholinergic systems appear mature by adolescence. Therefore, the relatively normal REM latency observed in depressed adolescents does not appear to be due to the inability of normal adolescents to mount REM sleep changes in response to cholinergic agents.

Basic and clinical studies have demonstrated the involvement of muscarinic cholinergic systems in the regulation of REM sleep (George et al. 1974; Hobson et al. 1993; Jones 1993; Shiromani and Gillin 1987). While acute administration of muscarinic agonists can shorten REM latency, increase REM activity and REM density, and reduce slow-wave sleep (Berkowitz et al. 1990; Riemann and Berger 1989; Riemann et al. 1988; Sitaram and Gillin 1980; Sitaram et al. 1977, 1978), acute administration of muscarinic cholinergic antagonists generally produce the opposite effects (Gillin et al. 1991b; Hohagen et al. 1994; Poland et al. 1989, 1997; Sagalés et al. 1969; Salin-Pascual et al. 1993; Sitaram et al. 1978). Based upon the pharmacologic profile of the compounds used to manipulate sleep, it appears that both M1 and M2 muscarinic receptor subtypes are involved in the regulation of REM sleep and its various elements (Gillin et al. 1993; Imeri et al. 1994; Velazquez-Moctezuma et al. 1989, 1991; Zoltoski et al. 1993). 


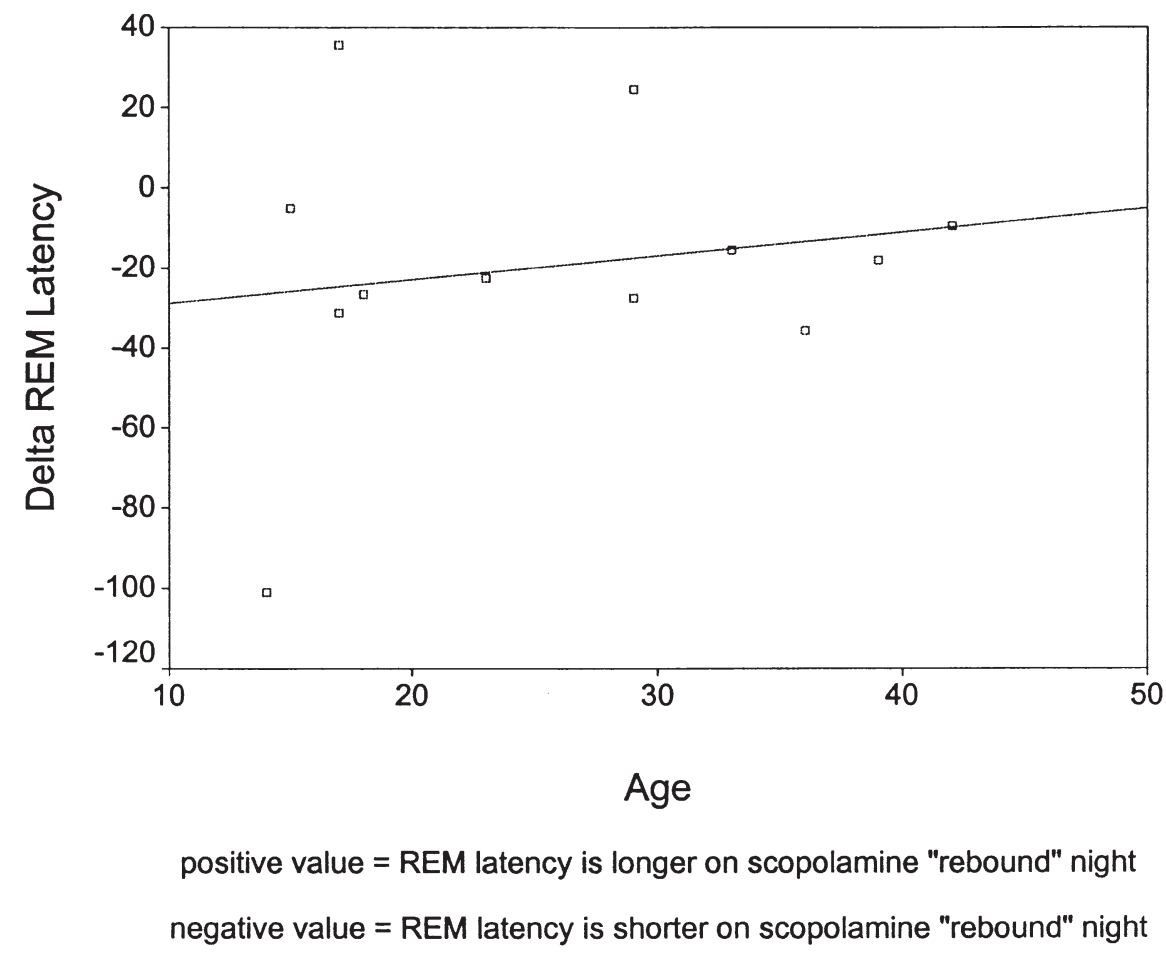

Figure 1. Delta REM latency (REM latency on the scopolamine-rebound night-REM latency on the placebo-rebound night) on the rebound night following scopolamine treatment.

The results from this study should be considered as preliminary findings due the modest sample sizes of the two groups. Despite this limitation, the study extends other reports showing a consistency between youngsters and adults in REM sleep changes on administration of cholinergic agents and antidepressants with strong anticholinergic properties (Dahl et al. 1994; Kupfer et al. 1979; McCracken et al. 1997; Shain et al. 1990).

Developmental differences in the suppression of tonic REM sleep measures in the context of comparable age-related effects on the phasic REM measures suggest that the neuro-regulatory systems controlling these two aspects of REM sleep may be different, and may mature at different rates (Cabeza et al. 1994; Siegel 1994). Lauer et al. (1991), examining developmental differences in EEG sleep changes in depressed patients, noted that REM density is relatively unaffected by age and that it may be a more consistent psychobiological marker for depression. We also found higher REM activity and REM density in adolescent depressed patients with no evidence of reduced REM latency (McCracken et al. 1997).

The subtle developmental differences in the REM sleep responses to scopolamine observed in the present investigation support previous reports of age-related differences in hypothalamic-pituitary-adrenal response to cholinergic challenge and in muscarinic receptor binding in animals (McCracken and Poland 1990; Sutin et al. 1986), as well as developmental differences in the prevalence of neuroleptic-induced acute dystonic reac- tions (Keepers et al. 1983). In order to further clarify the nature and extent of developmental differences in the cholinergic regulation of REM sleep during normal development and in depression, future investigations should include larger samples of both normal controls and depressed patients from various age groups, including younger children. In addition to the cholinergic systems, REM sleep regulation may also involve the aminergic systems (McCarley and Massaquoi 1992; McCarley et al. 1995; Myers et al. 1993). Future studies also should focus on the aminergic and cholinergic systems simultaneously (Seifritz et al. 1998) both in adults and in juvenile populations.

In summary, these preliminary results do not support the hypothesis that substantial developmental differences in the cholinergic regulation of REM sleep may be associated with reduced prevalence of REM sleep abnormalities in depressed adolescents. There are, however, minor developmental differences in some REM sleep measures. As opposed to a primary dysregulation of the cholinergic neurotransmission, developmental variations in other neuro-regulatory systems controlling REM sleep should be explored in the future.

\section{ACKNOWLEDGMENTS}

This study was supported in part by NIMH Scientist Development Award MH01419 (to UR), NIMH Research Scientist De- 
velopment Award MH00534 (to REP), the NIMH Research Center on the Psychobiology of Ethnicity MH47193, MH34471, and NIH General Clinical Research Center Grant RR00425. The authors thank Manny Madamba for technical assistance and Debbie Hanaya for administrative support.

\section{REFERENCES}

Armitage R, Emslie G, Rintelmann J (1997): The effect of fluoxetine on sleep EEG in childhood depression: A preliminary report. Neuropsychopharmacology 17:241-245

Benca RM, Obermeyer WH, Thisted RA, Gillin JC (1992): Sleep and psychiatric disorders. Arch Gen Psychiatry 49:651-668

Berkowitz A, Sutton L, Janowsky DS, Gillin JC (1990): Pilocarpine, an orally active muscarinic cholinergic agonist, induces REM sleep and reduces delta sleep in normal volunteers. Psychiatry Res 33:113-119

Birmaher B, Ryan ND, Williamson DE, Brent DA, Kaufman J (1996): Child and adolescent depression: A review of the past 10 years. Part II. J Am Acad Child Adolesc Psychiatry 35:1575-1583

Borbely AA (1982): A two process model of sleep regulation. Human Neurobiol 1:195-204

Cabeza RDJ, Zoltoski RK, Gillin JC (1994): Biochemical pharmacology of sleep. In Chokroverty S (ed), Sleep Disorders Medicine. Boston, MA, Butterworth-Heinemann, pp 37-56

Coyle JT, Yamamura H (1976): Neurochemical aspects of the ontogenesis of cholinergic neurons in the rat brain. Brain Res 118:429-440

Dahl RE, Ryan ND, Perel J, Birmaher B, Al-Shabbout M, Nelson B, Puig-Antich J (1994): Cholinergic REM induction test with arecoline in depressed children. Psychiatry Res 51:269-282

Emslie G, Kowatch R (1996): Predictors of remission and recurrence in depressed children and adolescents. Presented at the 43rd Annual Meeting of the American Academy of Child and Adolescent Psychiatry, Philadelphia, PA, October 22-27

George R, Haslett WL, Jenden DJ (1974): A cholinergic mechanism in the brainstem reticular formation: Induction of paradoxical sleep. Int J Neuropharmacol 3:541552

Gillin JC, Sutton L, Ruiz C, Darko D, Golshan S, Risch SC, Janowsky D (1991a): The effects of scopolamine on sleep and mood in depressed patients with a history of alcoholism and a normal comparison group. Biol Psychiatry 30:157-169

Gillin JC, Sutton L, Ruiz C, Golshan S, Hirsch S, Warmann C, Shiromani P (1991b): Dose dependent inhibition of REM sleep in normal volunteers by biperiden, a muscarinic antagonist. Biol Psychiatry 30:151-156

Gillin JC, Salin-Pascual R, Velazquez-Moctezuma J, Shiromani P, Zoltoski R (1993): Cholinergic receptor subtypes and REM sleep in animals and normal controls. In Cuello AC (ed), Progress in Brain Research, Vol. 98. New York, Elsevier Science Publishers, pp 379-387

Gillin JC, Wyatt RJ, Fram D, Snyder F (1978): The relationship between changes in REM sleep and clinical improvement in depressed patients treated with amitriptyline. Psychopharmacology 59:267-272

Hamilton M (1960): A rating scale for depression. J Neurol Neursurg Psychiatry 25:56-62

Hobson JA, Datta S, Calvo JM, Quattrochi J (1993): Acetylcholine as a brain state modulator: Triggering and longterm regulation of REM sleep. In Cuello AC (ed), Progress in Brain Research, Vol. 98. New York, Elsevier Science Publishers, pp 389-404

Höchli D, Riemann D, Zulley J, Berger M (1986): Initial REM sleep suppression by clomipramine: A prognostic tool for treatment response in patients with major depressive disorder. Biol Psychiatry 21:1217-1220

Hohagen F, Lis S, Riemann D, Krieger S, Meyer C, Fritsch Montero R, Grunze H, Berger M (1994): Influence of biperiden and bornaprine on sleep in healthy subjects. Neuropsychopharmacology 11:29-32

Imeri L, Bianchi S, Angeli P, Mancia M (1994): Selective blockade of different brain stem muscarinic receptor subtypes: Effects on the sleep-wake cycle. Brain Res 636:68-72

Jones BE (1993): The organization of central cholinergic systems and their functional importance in sleep-waking states. In Cuello AC (ed), Progress in Brain Research, Vol. 98. New York, Elsevier Science Publishers, pp 61-71

Keepers GA, Clappison VJ, Casey DE (1983): Initial anticholinergic prophylaxis for acute neuroleptic induced extrapyramidal syndromes. Arch Gen Psychiatry 40:1113-1117

Knowles JB, MacLean AW (1990): Age-related changes in sleep in depressed and healthy subjects. Neuropsychopharmacology 3:251-259

Kovacs M (1996): Presentation and course of major depressive disorder during childhood and later years of the life span. J Am Acad Child Adolesc Psychiatry 35:705-715

Kupfer D (1976): REM latency: a psychobiologic marker for primary depressive disease. Biol Psychiatry 11:159-174

Kupfer DJ, Coble P, Kane J, Petti T, Conner CK (1979): Imipramine and EEG sleep in children with depressive symptoms. Psychopharmacology 60:117-123

Kupfer DJ, Ehlers CL, Frank E, Grochocinski VJ, McEachran AB, Buhari A (1994): Persistent effects of antidepressants: EEG sleep studies in depressed patients during maintenance treatment. Biol Psychiatry 35:781-793

Lauer CJ, Riemann D, Wiegand M, Berger M (1991): From early to late adulthood: Changes in EEG sleep of depressed patients and healthy volunteers. Biol Psychiatry 29:979-993

McCarley RW, Massaquoi SG (1992): Neurobiological structure of the revised limit cycle reciprocal interaction model of REM cycle control. J Sleep Res 1:132-137

McCarley RW, Greene RW, Rainnie D, Portas CM (1995): Brainstem neuromodulation and REM sleep. Sem Neurosci 7:341-354

McCracken JT, Poland RE (1990): Peripubertal and adult rats differ in their hypothalamic-pituitary response to cholinergic challenge. J Child Adolesc Psychopharmacol 1:141-145

McCracken JT, Poland RE, Lutchmansingh P, Edwards C (1997): Sleep electroencephalographic abnormalities in 
adolescent depressives: Effects of scopolamine. Biol Psychiatry 42:577-584

Mirmiran M, Van De Poll NE, Corner MA, Van Oyen HG, Bour HL (1981): Suppression of active sleep by chronic treatment with chlorimipramine during early postnatal development: Effects upon adult sleep and behavior in the rat. Brain Res 204:129-146

Myers JE, Buysse DJ, Thase ME, Perel J, Miewald JM, Cooper TB, Kupfer DJ, Mann JJ (1993): The effects of fenfluramine on sleep and prolactin in depressed inpatients: A comparison of potential indices of brain serotonergic responsivity. Biol Psychiatry 34:753-758

Poland RE, McCracken JT, Lutchmansingh P, Lesser IM, Tondo L, Edwards C, Boone KB, Lin K-M (1997): Differential response of rapid eye movement sleep to cholinergic blockade by scopolamine in currently depressed, remitted, and normal control subjects. Biol Psychiatry 41:929-938

Poland RE, Tondo L, Rubin RT, Trelease RB, Lesser IM (1989): Differential effects of scopolamine on nocturnal cortisol secretion, sleep architecture, and REM latency in normal volunteers: Relation to sleep and cortisol abnormalities in depression. Biol Psychiatry 25:403-412

Rao U, Dahl RE, Ryan ND, Birmaher B, Williamson DE, Giles DE, Rao R, Kaufman J, Nelson B (1996): The relationship between longitudinal clinical course, and sleep and cortisol changes in adolescent depression. Biol Psychiatry 40:474-484

Rechtschaffen A, Kales A (1968): A Manual of Standardized Terminology, Techniques and Scoring System for Sleep Stages of Human Subjects. Los Angeles, Brain Information Service/Brain Research Institute, UCLA

Riemann D, Berger M (1989): EEG sleep in depression and in remission and the REM sleep response to the cholinergic agonist RS 86. Neuropsychopharmacology 2:145-152

Riemann D, Joy D, Höchli D, Lauer C, Zulley J, Berger M (1988): Influence of the cholinergic agonist RS 86 on normal sleep: Sex and age effects. Psychiatry Res 24:137-147

Rush AJ, Giles DE, Jarrett RB, Feldman-Koffler F, Debus JR, Weissenburger J, Orsulak PJ, Roffwarg HP (1989): Reduced REM latency predicts response to tricyclic medication in depressed outpatients. Biol Psychiatry 26:61-72

Sagalés T, Rill S, Domino EF (1969): Differential effects of scopolamine and chlorpromazine on REM and NREM sleep in normal male subjects. Clin Pharmacol Therap 10:522-529

Sagalés T, Rill S, Domino EF (1975): Effects of repeated doses of scopolamine on the electroencephalographic stages of sleep in normal volunteers. Clin Pharmacol Therap 18:727-732

Salin-Pascual RJ, Granados-Fuentes D, Galicia-Polo, Nieves E, Gillin JC (1993): Development of tolerance after repeated administration of a selective muscarinic M1 antagonist biperiden in healthy human volunteers. Biol Psychiatry 33:188-193

Seifritz E, Gillin JC, Rapaport MH, Kelsoe JR, Bhatti T, Stahl SM (1998): Sleep electroencephalographic response to muscarinic and serotonin ${ }_{1 \mathrm{~A}}$ receptor probes in patients with major depression and in normal controls. Biol Psychiatry 44:21-33
Shain BN, Naylor M, Shipley JE, Alessi N (1990): Imipramine effects on sleep in depressed adolescents: A preliminary report. Biol Psychiatry 28:459-462

Sharpley AL, Cowen PJ (1995): Effect of pharmacologic treatments on the sleep of depressed patients. Biol Psychiatry 37:85-98

Shiromani PJ, Gillin JC (1987): Acetylcholine and the regulation of REM sleep: Basic mechanisms and clinical implications for affective illness and narcolepsy. Ann Rev Pharmacol Toxicol 27:137-156

Siegel JM (1994): Brainstem mechanisms generating REM sleep. In Kryger MH, Roth T, Dement WC (eds), Principles and Practice of Sleep Medicine. Philadelphia, PA, W.B. Saunders Company, pp 125-144

Sitaram N, Gillin JC (1980): Development and use of pharmacological probes of the CNS in man. Evidence of cholinergic abnormality in primary affective illness. Biol Psychiatry 15:925-955

Sitaram N, Mendelson WB, Wyatt RJ, Gillin JC (1977): The time-dependent induction of REM sleep and arousal by physostigmine infusion during normal human sleep. Brain Res 122:562-567

Sitaram N, Moore AM, Gillin JC (1978): Induction and resetting of REM sleep rhythm in normal man by arecholine: Blockade by scopolamine. Sleep 1:83-90

Spitzer RL, Williams JBW, Gibbons M (1986): The Structured Clinical Interview for DSM-III-R (SCID). New York, New York State Psychiatric Research Institute

Staner L, Kerkhofs M, Detroux D, Leyman S, Linkowski P, Mendlewicz J (1995): Acute, subchronic and withdrawal sleep EEG changes during treatment with paroxetine and amitriptyline: A double-blind randomized trial in major depression. Sleep 18:470-477

Sutin EL, Shiromani PJ, Kelsoe JR, Storch FI, Gillin JC (1986): Rapid-eye movement sleep and muscarinic receptor binding in rats are augmented during withdrawal from chronic scopolamine treatment. Life Sci 39:2419-2427

Thase ME, Buysse DJ, Frank E, Cherry CR, Cornes CL, Mallinger AG, Kupfer DJ (1997): Which depressed patients will respond to interpersonal psychotherapy? The role of electroencephalographic sleep profiles. Am J Psychiatry 154:502-509

Teicher MH, Glod CA, Harper D, Magnus E, Brasher C, Wren F, Pahlavan K (1993): Locomotor activity in depressed children and adolescents: I. Circadian dysregulation. J Am Acad Child Adolesc Psychiatry 32:760-769

Velazquez-Moctezuma J, Gillin JC, Shiromani PJ (1989): Effect of specific M1, M2 muscarinic receptor agonists on REM sleep generation. Brain Res 503:128-131

Velazquez-Moctezuma J, Shalauta M, Gillin JC, Shiromani PJ (1991): Cholinergic antagonists and REM sleep generation. Brain Res 543:175-179

Vogel GW, Buffenstein A, Minter K, Hennessey A (1990): Drug effects on REM sleep and on endogenous depression. Neurosci Beh Rev 14:49-63

Zoltoski RK, Velazquez-Moctezuma J, Shiromani PJ, Gillin JC (1993): The relative effects of selective $M_{1}$ muscarinic antagonists on rapid eye movement sleep. Brain Res 608:186-190 